\title{
Determinaciones abstractas y noción conceptual de la educación. Una lectura crítica a la acumulación del saber
}

\author{
Abstract determinations and conceptual notion of education. A critical reading of the \\ accumulation of knowledge
}

\author{
Ernesto Herra Castro \\ Universidad Nacional, Costa Rica, ernesto.herra.castro@una.cr
}

Fecha de recepción: 27/07/2016. Fechas de reenvíos: 9/9/2016 -10/9/2016, 7/02/2017-8/0/2017, 18/05/2017 - 22/05/2017, Fecha de aprobación: 19/06/2017.

Fecha de publicación: 01/07/2017.

\begin{abstract}
Resumen: Desde una perspectiva histórica de larga duración, se intenta dar cuenta de algunas de las determinaciones conceptuales de la educación, a partir de la identificación de siete momentos educativos medulares que han acompañado a nuestra especie desde su aparición, hacia el 130.000 a.C., hasta la formalización del saber humano, propio de la tradición helena, durante los siglos VI y III a.C. Se intenta así confrontar el helenocentrismo que atraviesa la lógica y dinámicas educativas, para impulsar una discusión más allá de ellas. Se trata de identificar condiciones intelectuales y materiales que permitan producir y reproducir la vida en el único planeta de la vía láctea en capacidad de hacerla posible.
\end{abstract}

Palabras clave: aprendizaje; enseñanza; sabiduría; conocimiento; comunidad; sociedad.

\begin{abstract}
From a long-term historical perspective, some conceptual determinations regarding education are presented identifying seven core educational moments in mankind. This overview includes history starting from the appearance of the modern human in about 130000 BC until the formalization of human knowledge, which was typical of the Hellenistic tradition during the 6 th and 3rd centuries $B C$. The Hellenocentric point of view influencing educational dynamics and logic is confronted to promote discussion beyond this point of view. The paper is aimed at identifying the intellectual and material conditions that allow producing and reproducing life on the only planet in the Milky Way where life is possible.
\end{abstract}

Keywords: learning; teaching; wisdom; knowledge; community; society. 
Vol 37, N 55, (1-17), EISSN: 2215-2997, julio - diciembre, 2017

URL: www.revistas.una.ac.cr/abra DOI: http://dx.doi.org/10.15359/abra.37-54.1

\section{Introducción}

A lo largo de los 130.000 años de historia en la que nuestra especie ha ocupado la tierra', el ser humano se ha enfrentado a su entorno a partir del desarrollo de un aparataje cognitivo como "un proceso continuo que sumerge sus raíces en el organismo biológico, prosigue a través de la niñez y de la adolescencia, y se prolonga en el sujeto adulto hasta los niveles de la actividad científica", (García, 2000, p. 60). La tesis anterior tendría presupuesto el hecho de que nuestra mismidad humana ha debido acumular y reproducir los saberes y conocimientos "cuyas coordinaciones constituirán el comienzo de lo que serán procesos cognoscitivos, así como continuidad en los mecanismos cognoscitivos pre científicos y científicos", (García, 2000, p. 6).

Según la primera tesis sobre la construcción del conocimiento, García (2000), señala que la acumulación y reproducción de los saberes de nuestra especie es una continuidad de carácter funcional y no estructural. Lo anterior "se refiere a los mecanismos formadores de nociones, ideas, conceptualizaciones y teorizaciones (desde los niveles más rudimentarios, hasta los más altos niveles de abstracción), sin que haya obviamente, continuidad en los contenidos, ni en la forma de organización" (pp. 60-61).

Dado que los conceptos verdaderos (Dussel, 2014a) tienen una serie de determinaciones, momentos constitutivos que determinan su contenido "...las 'diferentes partes objetivas (gegenständlichen Bestandtheile)' (337-338; I, 37), son separadas en las determinaciones abstractas con las que se desarrolla el concepto. Por su parte, el 'concepto' puede ponerse en una 'forma abstracta general' (la esencia) o puede manifestarse como 'una forma fenoménica'. El concepto, además, debe distinguirse de la mera 'apariencia empírica (empirischen Schein)' (387, $17 ; 1,87)^{\prime \prime}$ (p. 23).

Lo que he intentado hacer aquí, apoyado en lo anterior, es identificar y nombrar algunos de los momentos constitutivos, determinaciones abstractas, que impulsan la noción conceptual de educación que mostraré en su forma abstracta general. Hacer lo anterior me permitirá posicionarme críticamente, en tanto lectura de lo posible (Zemelman, 2012), respecto del orden helenocéntrico que atraviesa la dinámica educativa moderna para poder ir más allá de ella.

En este primer acercamiento, he intentado identificar los momentos educativos que dan forma constitutiva a la educación durante los dos primeros sistemas éticos ${ }^{2}$ que atraviesan

1 La educación, como instrumento técnico para la producción y reproducción de los saberes que nuestra especie ha acumulado a lo largo de su historia, ha partido del presupuesto de nuestra madre común en tanto planeta, de raíz latina, cuya totalidad de sentido está comprendido por el ser que se ubica en el centro de la creación. El presente esfuerzo, al contrario, se abre a la reflexión de la vida en tanto cosmos, de raíz griega, cuya totalidad de sentido contiene a "las cosas reales conocidas o no por el ser humano. La totalidad de los astros, la vida, lo real, en cuanto es algo constituido de suyo, desde su propia esencia" (Dussel, 2011, p. 54).

2 Estos son el egipcio-mesopotámico (desde el V milenio a.C.); el indoeuropeo (desde el siglo XX a.C.); el asiático-afromediterráneo (desde el siglo IV d.C.); y el sistema-mundo moderno (vigente desde 1492), (Dussel, 2009). 
nuestra humanidad. Hacer lo anterior, permite identificar algunas de las determinaciones que han quedado subsumidas en el proceder racional occidental, de forma tal, que la institución educativa, como posibilidad para producir y reproducir la vida comunitaria de nuestra especie, ha quedado reducida a la pretensión de dominio contenida en el tipo de pregunta desplegada por la Grecia clásica (siglos IV y III a.C.) (Herra y Baraona, 2015a; Herra y Baraona, 2015b).

\section{Educación: producción y continuación del saber acumulado}

La separación entre el conocimiento y la sabiduría forma parte de una jerarquización respecto del tipo de conocimiento occidental y el no occidental, denominado en Quijano (2000) epistemología del poder. De lo que se trata es de impulsar un orden que gire en torno a un solo tipo de noción epistémica que posiciona, en un lugar de privilegio, los conocimientos, saberes, estéticas, credos, tradiciones culturales, etc., occidentales sobre los no occidentales. Mientras que el conocimiento es concebido como el producto del saber científico, la sabiduría es un principio humano mucho más amplio que abarca lo científico, pero que no se limita a él. Mientras que el conocimiento es un tipo de sabiduría que ha sido formalizada e institucionalizada según los valores, juicios, prejuicios y subjetividades de aquellos pueblos que, desde la Grecia clásica (siglos IV y III a.C.), se han impuesto militar y, posteriormente, de forma racional sobre otros; la sabiduría, por el contrario, reúne los saberes múltiples y diversos que han hecho posible la producción y reproducción de la vida humana en el cosmos.

Nuestra especie, que es el resultado del desarrollo evolutivo de distintos tipos de homínidos que sufrieron la separación sus líneas evolutivas hace alrededor de 5-7 millones de años, se irguió en dos patas y comenzó a florecer en un momento ubicado entre 10 y 5 millones de años a.C., al tiempo que otras especies de primates, que para entonces eran más de 20, comenzaron a declinar (Leakey y Lewin, 1999).

La postura bípeda de este particular simio, está apoyada en varias hipótesis entre las que se encuentra la necesidad de desarrollar herramientas, porque este necesitaba cazar; $y$, entre otras, la del anatomista estadounidense Owen Lovejoy (citado en Leakey y Lewin, 1999, pp. 85-87), la cual señala que nuestra especie tendió a erguirse producto de la necesidad de llevar cosas sí, pero esta necesidad surgió producto de gran parte de nuestra constitución biológica que demanda grandes suministros de energía y un rendimiento mayor para la procreación de la especie. Además, urge de mayor dotación de fuentes energéticas para las hembras, lo que le permitió que aquellos simios erguidos, cuyas extremidades le permitían transportar cosas, ser más proclives a la reproducción y, finalmente, prevalecer. 
El momento evolutivo anterior sugiere una estrecha relación con el desarrollo de la capacidad cognitiva asociada con el instinto. De esta forma, el aprendizaje instintivo ${ }^{3}$ se integra en lo que se propone como el primer momento constitutivo de la dinámica educativa. La anterior estaría compuesta, según lo que proponemos aquí, por el aprendizaje que permite a nuestra especie establecerlas coordinaciones con los objetos en su exterioridad para comprenderlos, relacionarse con ellos, nombrarlos (García, 2000), acompañada de la enseñanza, como mecanismo técnico que propicia la continuidad de los saberes acumulados. De esta forma, este momento educativo está impulsado por la observación y la capacidad de aprehender de ella. Este aprendizaje tiene un horizonte comunitario, ya que hasta hace unos 9.000 años la humanidad recolectaba frutos y perseguía animales allí donde podía para poder alimentarse. Las duras condiciones del clima, los largos inviernos, la ferocidad de sus depredadores, les había cohesionado como un solo sujeto con miras a garantizar la reproducción de la vida. Lo anterior permite señalar, junto al filósofo y epistemólogo argentino/mexicano Enrique Dussel, que "la comunidad es el modo de existencia humana y punto de partida de la vida económica" (Dussel, 2014b, p. 24). Ante lo anteriormente señalado me atrevo a proponer este como el momento de aprendizaje instintivo para la producción de la vida comunitaria.

Hacia el octavo milenio a.C., la humanidad contaba con unos ocho millones de individuos, los cuales, por medio de un proceso gradual, aprendieron a almacenar alimentos y a mantener algunos de los animales que cazaban con vida para poder contar con ellos en momentos posteriores, tal como fue el caso de algunas especies que lograron domesticar para el trabajo (Asimov, 2011). De esta forma surge, en interconexión e interdependencia con la vida, lo que podríamos pensar como otro momento educativo, determinación abstracta, vinculado directamente con la enseñanza para la vida comunitaria y se deja atrás lo instintivo. Este momento marca el inicio de una mediación pedagógica para la vida, donde nuestra especie comprende la importancia de un hecho dado para su propia producción y reproducción y, por lo tanto, busca recrearlo. Según Dussel (2011), "la transmisión de la cultura acumulada se transfiere gracias a sistemas pedagógicos, desde los más antiguos y simples (como enseñar el pulido de una piedra), hasta los más recientes y complejos (como enviar un satélite a la luna o tomar decisiones por computadora), los sistemas pedagógicos se han ido optimizando" (p. 144). Sin embargo, es clave, para nuestros propósitos, mostrar el sentido comunitario que el proyecto mediado por la producción y reproducción de la vida comunitaria de nuestra especie tuvo, en un inicio, para confrontarlo con la racionalidad individual, egoísta, formal, capitalista de la racionalidad contenida en el proyecto de la modernidad (Bautista, 2010).

3 Valga la pena señalar que nuestra especie se nutrió de los saberes acumulados por los otros tipos de homínidos que surgieron previo a nuestra aparición hacia el 130.000 a.C., (Asimov, 2011; Dussel, 2009; Leakey, R. y Lewin, R., 1999; Prieto, 2010). Sin embargo, dado que son el conjunto de relaciones comunitarias y sociales que nuestra especie ha desarrollado desde su aparición hasta la actualidad, las que han tensado las posibilidades de producción y reproducción de la vida, hoy manifiestas a escala planetaria, es que el Sujeto alrededor del que se construye la presente reflexión es humano y no otro. 
Siendo que la vida comunitaria es el punto de partida de la actividad económica (Dussel, 2011; Dussel, 2014b), las necesidades comunitarias urgían de la creación de un producto que satisficiera la necesidad, el cual impulsaba la organización de un tipo particular de relaciones económicas en torno a la vida. Lo anterior obligó a formas diferenciadas de organización que buscaran atender la compleja composición biológica y social de nuestra especie, lo cual fue posible a través de la transformación de la naturaleza (concebida posterior a la imposición de la razón helena como materia primera), fruto de la creatividad, capacidad y trabajo humano, para obtener productos (concebidos de esta forma posterior a la imposición de la razón moderna), que satisficieran nuevas y más complejas necesidades.

La creación de los productos satisfactores de necesidad, impulsó la primera división técnica del trabajo en la que, por un lado, se dividieron las actividades humanas en dos grandes oficios: la agricultura y el pastoreo, al tiempo que las tareas entre hombres y mujeres se especializaron de forma tal que se garantizara la producción y reproducción de la vida de la especie. De esta forma, y no por otra razón, las mujeres estuvieron más relacionadas con el nacimiento, la alimentación, la educación primaria (socialización primaria), de los miembros de la comunidad; mientras los hombres se dedicaron a la obtención de los recursos materiales para la reproducción de la vida como la caza o la defensa del grupo (Dussel, 2014b).

La división técnica del trabajo en estas dos grandes áreas obligó a cazadores y comunidades de pastoreo, a mantenerse en constante movimiento en la búsqueda de pastos verdes, lo que les impulsó a llevar una vida nómada (Asimov, 2011). Por otro lado, aquellas comunidades que se dedicaron a la siembra debieron pasar largos periodos en el mismo espacio geográfico ya que a las plantas, así como la vida misma, hay que cuidarlas, limpiarles la maleza y mantener a los animales alejados.

Debido a que las comunidades agrícolas se habían dotado de mayores y más complejas herramientas técnicas que las comunidades de nómadas cazadores y que las primeras habían creado el conocimiento para almacenar los distintos productos satisfactores de necesidad, estas fueron víctimas, constantemente, de los embates militares de los pueblos nómadas. Desde el 10000 a.C., las confrontaciones bélicas entre pueblos cazadores nómadas y agricultores fueron cada vez más frecuentes (Asimov, 2011) y la guerra, como institución, se consolidó como instrumento de mediación de los conflictos humanos. Lo anterior permitió ir desarrollando y consolidando una conciencia de territorialidad y propiedad que ha impulsado, de manera ininterrumpida desde entonces, la carrera armamentística y militar ligada a lo que sugiero como un tercer momento educativo en el que, previa racionalización y objetivación del trabajo humano, se adquiere mayor grado de perfeccionamiento. De esta forma, la administración, el dominio, el control, la posesión de un saber, solo es posible si se recurre a un proceso de enseñanza a través del cual, la repetición de una actividad basada en la observación, la generación de preguntas, la 
reflexión, permiten reproducir y mejorar los productos satisfactores de necesidad previamente desarrollados.

Mientras que el primer momento educativo, está caracterizado por la iluminación de las mentes capaces de traducir en ideas y conceptos, muy básicos aún, aquello observado que permite la producción y reproducción de la vida; el segundo momento educativo identificado y propuesto aquí, está caracterizado por la enseñanza como una actividad esencial para la vida comunitaria, en la cual el aprendizaje surge, ya no como un acto instintivo sino como la capacidad de observación, duda y asombro, que desarrolla nuestra especie por su compleja capacidad de raciocinio, como la capacidad de aprender y reproducir aquellas prácticas que le permiten hacer la vida posible; el tercer momento educativo propuesto está caracterizado por el desarrollo de las condiciones técnicas para la negación de la vida, razón por la que me he atrevido a nombrarlo de esta forma. Mientras que la complejidad y sofisticación que va adquiriendo nuestra especie le permite mayores y mejores condiciones para hacer la vida posible, el poder hacerlo está atravesado por la negación/destrucción de otras formas de vida, llevada hasta la hiperespecialización siglos más tarde, como la racionalidad de lo irracional (Marcusse, 2014).

Hacia el 5000 a.C., la agricultura se había desarrollado y consolidado como una práctica humana tanto en Egipto, donde se domesticó el trigo; en China, donde se domesticó el arroz; en Perú, donde se domesticó la quinua; como en México, donde se logró domesticar el maíz ${ }^{4}$. La capacidad de la humanidad ya no sólo de contar con los alimentos necesarios para reproducir la vida de su especie, sino de almacenarlos y tener la posibilidad de administrar la vida en el tiempo, marcó un momento de quiebre significativo en las relaciones humanas previamente existentes. De lo señalado anteriormente da cuenta Asimov (2011), cuando explica que grupos nómadas, que no tenían más alimento que el que lograban cazar o bien matar a uno de sus propios animales, se encontraban constantemente tentados y en la condición de invadir las ciudades agrícolas en las que se administran y guardan distintas formas de valor: sabiduría, conocimientos, bienes culturales o riquezas materiales (Asimov, 2011, pp.11-23).

Si bien, la vida comunitaria se realizaba y reproducía principalmente al lado del campo que le dotaba de los alimentosy materia prima para la producción de su vida, el sentido organizativo para la administración de esa vida comunitaria surgió en torno a las ciudades, las cuales permitieron almacenar los productos excedentes del trabajo comunitario. Las ciudades se convierten así en los principales focos de ataque de los pueblos nómadas, lo que utilizan las ciudades para

4 Durante el último periodo de glaciación, que se extendió desde hace unos 50000 años hasta hace unos 10000 años, las regiones polares de la tierra se cubrieron de hielo, disminuyendo la distancia entre la Isla del Mundo y el continente americano, al tiempo que el nivel del océano descendió hasta dejar un puente terrestre de unos 2100 kilómetros entre Asia y América del Norte que permitió el paso entre uno y otro lado hasta que en el sétimo milenio a.C. En el último de los años señalados el nivel del océano volvió a elevarse y dejó nuevamente separados a los continentes tal como los conocemos en la actualidad. Se cree, según la evidencia recabada (puntas de flecha y tecnología de caza similar), que el ser humano llegó procedente del extremo nororiental de Asia a América hacia el 25000 antes de nuestra era, lo que nos permite ubicar el momento histórico en el que nuestra humanidad puebla la redondez de la tierra. 
desarrollar las primeras formas de organización militar contra las amenazas provenientes de las bandas de nómadas, como sucedió en las ciudades de Menfis, Heliópolis, This o Tebas, o las ciudades de Ur, Asur, Babilonia o Susa, de Mesopotamia (lo que en la actualidad es Irak), o Persia (lo que en la actualidad es Irán), (Asimov, 2011, p. 24-65).

Ante lo anterior quisiera proponer un cuarto momento educativo, caracterizado por la imposición de un orden que gira en torno a la ciudad (lo urbano), desplazando al campo (la ruralidad), de su centralidad. A este cuarto momento educativo quisiera sugerirlo como origen de la tensión urbano/rural.

El desarrollo tecnológico propiciado por la guerra, tecnología de la no vida, propició el desarrollo de métodos para la obtención de cobre, hacia el 3500 a.C., y de bronce hacia el año 3000 a.C. De esta forma, se hace evidente que el desarrollo técnico para posibilitar la vida humana ha estado mediado por la tensión ética de su negación. Dicha tensión ha estado caracterizada por una dinámica de adaptación y resistencia al proyecto contenido en la modernidad, el cual se impulsa a través de la imposición de horizontes de sentido (logos) únicos que garanticen la apropiación excluyente del excedente de la comunidad (Dussel, 2014b), a favor de un orden aristócrata y oligarca (Herra y Baraona, 2015a).

\section{Saber y conocimiento en el sistema interregional egipcio-mesopotámico (desde el IV milenio a.C. ${ }^{5}$ )}

En un periodo histórico que tiene lugar en el IV milenio a.C., se desarrolló el primer momento ético de la humanidad, o sea, la urgencia de establecer una correlación directa entre las formas de pensar y de actuar como acción responsable para garantizar la producción y reproducción de la vida que, en un inicio, estuvo impulsada por un horizonte de sentido comunitario (Dussel, 2009). Este primer momento se desarrolla en el norte de África y el Medio Oriente (Egipto y Mesopotamia ${ }^{6}$ ), que llegará a expandirse hasta el continente asiático, denominado detrás de él como sistema interregional egipcio-mesopotámico.

Según la hipótesis sobre la monogénesis de las lenguas (Echeverría, 2015), el ser humano habría migrado de África hacia el Medio Oriente y Asia, y habría retrasado su llegada a Europa producto de los fríos de estos lugares, lo que habría posibilitado que el primer momento ético, filosófico, de exigencia de una actitud responsable para con los actos humanos, tuviese como cuna a África y Medio Oriente.

\footnotetext{
5 El sistema interregional egipcio-mesopotámico nace hacia el año 3100 a.C., unificados en torno a Menes, quien es considerado su primer Faraón, y culmina por sucumbir ante los embates sufridos bajo el asedio del Imperio Romano hacia el 30 a.C., cuando cae su última emperatriz: Cleopatra.

6

Actualmente Irak, Siria, Turquía, Irán y otros territorios del Cáucaso.
} 
El mundo del África negra bantú, constituye uno de los orígenes de la cultura egipcia (kmt en egipcio), (Dussel, 2009), la cual desarrolló las condiciones intelectuales y materiales para asegurar la producción y reproducción de la vida comunitaria desde el VIII milenio a.C., momento en el que logran impulsar la agricultura en el Sahara húmedo y que constituye el antecedente de la población del territorio en torno al río Nilo desde el V milenio a.C., (Dussel, 2009).

Así como los pueblos que dieron origen a Egipto se situaron a orillas del río Nilo, producto de la observación y experimentación a las que a través de su existencia se ha sometido la humanidad como un hecho consecuente con la necesidad de producir y reproducir vida, los pueblos migrantes de África dieron nacimiento a la actual Jarmo, ubicada en el sector septentrional de Irak, donde se extiende una cadena montañosa donde el aire se enfría y permite que del vapor condensado forme lluvia, lo que aseguraba agua a sus cosechas.

El período de mayor auge de sofisticación del conocimiento y la sabiduría egipcia-mesopotámica tiene lugar entre el 5000 a.C. y el 4500 a.C., periodo en el que se desarrollaron complejas redes de fosos, acequias, canales de irrigación, de agua potable que permitió, por primera vez, enfrentar el peligro de las inundaciones al tiempo que las fomentaron solo en los lugares deseados. Los conocimientos médicos así como su tecnología, les permitió afrontar los problemas de salud que experimentaban; ello les llevó, entre otros avances, a practicar la trepanación. Su complejo sistema hídrico se extendió hasta el Éufrates superior hacia el 5000 a.C., y al Éufrates inferior hacia el 4000 a.C., donde floreció lo que podríamos nombrar como la primera gran civilización occidental.

Lo anterior permite sugerir otro momento educativo pero, a diferencia de los anteriores, éste se constituye como un premomento a todo momento educativo posterior. Este tiene que ver con la necesidad de nuestra especie a desarrollar la vida en entornos atravesados por el agua, con acceso al agua. De esta forma quisiera sugerir aquí, un premomento educativo que propondré como acceso al agua como presupuesto de la vida.

A partir del 4000 a.C., las ciudades del Éufrates inferior se hicieron demasiado grandes y exigían de un tipo de organización que les permitiera asociarse, trabajar, cooperar para asegurar lo que hasta aquí la humanidad había hecho bien, es decir, asegurar la vida de la especie. Si bien los clanes, las tribus y naciones que contaban con un sistema basado en relaciones familiares y consanguíneas que tienen que obedecer a algún patriarca, les había permitido, contar con algún tipo de códigos éticos, el creciente número de habitantes en un mismo espacio geográfico, urgió de otras formas de organización por medio de las cuales las comunidades que coexisten en dicho espacio tuviesen un código ético común. De esta forma, las ciudades se convirtieron en una unidad espacial y política en capacidad de producir y reproducir la vida de su creciente población y dieron origen a las ciudades-estado. Así como ocurriese en las sociedades tribales, que eran guiadas y dirigidas por un patriarca, las nacientes ciudades-estado fueron guiadas y dirigidas por un rey. 
Los habitantes de las ciudades-estado de Egipto-Mesopotamia, no tenían claridad de dónde provenían las aguas del río que les daba vida, por qué en algunas oportunidades les azotaba con furia, por qué se desbordaba solo en algunos momentos y no en otros. Su primera respuesta ante estas inquietudes estuvo mediada por lo divino. Eran los dioses, seres con mayor poder que el humano, quienes por distintos motivos debían enojarse y actuar coléricos y furibundos contra los segundos. Desde este tipo de respuesta se llegó a la creencia de que a los dioses debía agradarles todo lo que les agradara a los seres humanos (Asimov, 2011), razón por la cual, desde los primeros rituales hasta la actualidad, existen distintas tradiciones de fe que ofrecen alimento a sus dioses para agradecerles y agradarles.

La creencia de que los dioses vivían en los cielos podría tener que ver con el hecho de que las sociedades agrícolas necesitan de la lluvia constantemente para sus cultivos, y siendo estas sociedades principalmente agrícolas, el sacrificio de animales y la quema de distintos tipos de manjares era una práctica común ya que el aroma que ascendía al cielo con el humo debía agradar a los dioses (Asimov, 2011). De ello dependían las cosechas, la lluvia, el sol, la victoria en batalla, así como también dependían de ello las inundaciones, los diluvios, las catástrofes, las sequías o las plagas. De la coexistencia pacífica entre los seres humanos dependía la guerra entre pueblos, entre vecinos, entre amigos que, ocasionalmente, podría llevar a la muerte: una consecuencia más de la coexistencia pacífica con los dioses de la que podía depender la vida de la humanidad toda.

Lo anterior propició el surgimiento de un poderoso cuerpo sacerdotal que se encargó no solo de la relación de las personas con los dioses, también lo hizo en las finanzas públicas, la hacienda, la administración pública y el cuerpo político de la ciudad-estado (Dussel, 2009). La estructura naciente de este orden tendió a desarrollarse de forma más compleja en las sociedades agrícolas, más no así en las nómadas o cazadoras.

Dado que el centro de relaciones sociales se estructuró en torno a un orden sacerdotal, el templo se ubicó como el centro de las ciudades. Estas ciudades impulsaron un orden social estructurado en torno a una racionalidad teológica que tuvo la claridad de que una condición necesaria para la vida humana y el surgimiento de su civilización, tiene que ver con la cercanía a los ríos (Nilo, Éufrates y Tigris), o a las lluvias. Lo último permite comprender por qué el cielo fue un referente en las relaciones cotidianas y el lugar de morada de sus dioses. Lo anterior impulsa a sugerir un quinto momento educativo asociado a la respuesta divina que ha dado nuestra especie ante los núcleos problemáticos (Dussel, 2009), que esta ha enfrentado, y que además ubican espacialmente la corporeidad de lo divino en los cielos. Dicho así, propongo éste como momento de espacialidad de lo divino y sacralidad del cielo.

Durante este sistema ético, cuando los faraones morían eran asumidos, en unos casos, o impuestos, en otros, como dioses a su pueblo (Waltari, 2005; Waltari, 2008). Esto fue una práctica 
retomada posteriormente en el orden greco/romano. Un ejemplo de ello es como el calendario romano, reproducido por la cristiandad, rinde homenaje al emperador Cayo Julio César, en el mes que lleva su nombre: Julio.

Hacia el 5000 a.C., los pueblos ubicados en Mesopotamia habían logrado reproducir y mejorar las prácticas y técnicas de agricultura, campo en el que alcanzando domesticar vacas y ovejas, así como mejorar distintos tipos de cereales; todo esto les permitió, al igual que lo hicieran más tarde otras grandes civilizaciones de la humanidad, expandir y difundir su sabiduría y conocimiento como condición posterior de garantizar la reproducción de la vida. La matemática jugó un papel clave en esto.

Entre los años 3300 y 3100 a.C., situada en la desembocadura del río Éufrates en el Golfo Pérsico, se encontraba la ciudad de Uruk. En ella se desarrolló el invento de la escritura, el cual ha sido uno de los mayores inventos creados por la humanidad. Lo anterior permitió elevar las cuentas de la ciudad, administrar con un registro los recursos disponibles y especializar la guerra (Asimov, 2011).

Egipto, en realidad Egi-pto o Co-pto, significa los adoradores de Ptah, quien es el dios de Menfis, ciudad en la que el Faraón Aha, de la II Dinastía, es el dios de lo universal cuya creación proviene de su corazón (Horus), y por medio de la razón, la palabra, la sabiduría (Thot), (Dussel, 2009), es el ejemplo más claro de que el universo ha sido creación divina. Lo anterior es compartido por la tradición cristiana (Proverbios 8-9), y podría ser comparable con el Quetzalcóatl de la tradición mexicana.

Según la cosmogonía egipcia, el cosmos o la humanidad, tienen un orden o una regla universal que es concebida como Maat, verdad o ley natural, que ha sido creación de Thot para revelarnos las verdades del universo. Esta creación se expresa a través de los números, las nociones del cálculo, la comprensión de los astros, el conocimiento geográfico o los signos de la escritura. Anterior a esta creación, el ser humano concebía las cosas enfrente suyo en términos de uno, par o muchos. Según la tradición egipcia-mesopotámica fue Maat quien dio las condiciones racionales para desligar el concepto abstracto, el número y el objeto (Dussel, 2009).

La capacidad de abstracción con que cuenta nuestra especie le permitió a griegos y romanos crear un sistema numérico basado en el número 10; a los celtas y los mayas utilizar un sistema numérico basado en el número 20; a los sumerios, acadios, amorreos, en fin, los babilonios utilizar un sistema numérico basado en el número 60 (Prieto, 2010, pp. 266-275).

La importancia en el origen y creación de un sistema numérico tiene que ver no solo con la representación cuantitativa de los objetos contenidos en la realidad que se intenta representar, lo que nos ha permitido desarrollar un sistema de mediación y cálculo de las distancias, 
superficies, volúmenes, velocidades, presiones, tiempos, pesos, temperaturas, compras, ventas, etc., o sea, nos ha dado las condiciones intelectuales para desarrollar el complejo sistema social al que hemos dado forma. Sin embargo, no fueron sino los egipcios-babilonios, los mayas y los indios quienes le aportaron a la humanidad la noción del cero.

Lo anterior marca un sexto momento educativo basado en el hecho de que, hasta entonces, la forma en que el ser humano se había enfrentado con el mundo, había sido a través de lo que posteriormente será denominado método inductivo. En éste se establece un movimiento que va de lo concreto hacia lo abstracto. De la cosa dada como un hecho basado en la experiencia, hacia la elaboración de una idea, hipótesis, teoría o ley. Sin embargo, lo que comienza a surgir con el origen de un sistema numérico culmina por invertir lo anterior. A partir de ahora, la idea, hipótesis, teoría o ley desarrollada por el ser humano, le permitirá explicar hechos, controlar la naturaleza, predecir fenómenos naturales e incluso enfrentar, en mejores condiciones, las adversidades que hasta entonces habían marcado la historia evolutiva de nuestra especie. En términos científicos este proceder metódico recibe el nombre de método explicativo.

Me gustaría sugerir, para este sexto momento educativo, en el que los saberes adquiridos a lo largo del tiempo cobran un sentido racional y explicativo, el nombre de saber teórico, que dista aún del formalismo que caracterizará la tradición filosófica griega posterior al siglo VI a.C., pero que, basándose en el desarrollo de los saberes adquiridos a lo largo de miles de años, adquieren un mayor grado de sofisticación conceptual y categorial que permiten relacionar las concepciones de la nada, el cero y el infinito.

En el campo científico la teoría tendrá el estatus de verdad y esta verdad científica se ha dotado, desde este momento, de un fuerte componente de cuantificación o medición que fue adquiriendo el saber matemático. Sin embargo, la formalización de un método y la incorporación matemática en él se darán hasta muchos siglos más tarde, por lo que no podemos hablar en este momento de conocimiento científico, sino de un saber con mayor nivel de complejidad y abstracción, al haber sido incorporada la matemática en la compresión y relación práctica con el mundo conocido. De esta forma, la matemática materializa y refleja la capacidad de abstracción del pensamiento humano con el que la necesidad e interés de controlar el medio en el que éste se desarrolla se ha hecho posible. Esto no significa, que la ciencia sea el mejor o superior de los saberes. Significa que es un saber sofisticado, hasta el nivel de híper especialización, que ha sido producido por la acumulación del saber humano a través de sus miles de años de existencia.

El desarrollo de la matemática permitió el impulsó de nuevas y más complejas instituciones humanas como el calendario, el año de 12 meses, el día de 24 horas, la hora de 60 minutos y el minuto de 60 segundos. 
Las condiciones materiales e intelectuales para la producción y reproducción de la vida le han permitido a la humanidad crear las condiciones para el desarrollo de saberes con mayor nivel de sofisticación; este desarrollo tenderá a formalizarse cada vez más, sin necesariamente ser superior a los alcances logrados y acumulados por la humanidad durante este primer periodo de la historia de las eticidades (Dussel, 2009, p. 24).

\section{Saber y conocimiento en el sistema interregional indo-europeo (desde el siglo XX a.C.)}

Si bien la ciencia es uno entre muchos otros saberes posibles, quizá es el que cuente con mayores niveles de sofisticación formal, debido a que la posibilidad de producir y reproducir la vida humana ha urgido de formas metódicas, sistemáticas y rigurosas que permitan mayor comprensión acerca del mundo del que somos parte, ha sido ella la responsable en el impulso de la vocación y voluntad de dominio que la humanidad ha desplegado consigo misma y con todas las otras formas de vida. La afirmación anterior guarda relación con el hecho de que al formalizar la ciencia, se formalizaron también los presupuestos filosóficos, sexistas/racistas/ clasistas ${ }^{7}$, de los que esta parte (Herra y Baraona, 2015a).

Según Aristóteles (2007), "...la ciencia de adquirir tiene principalmente como objeto el dinero, y cómo su fin principal es el descubrir los medios de multiplicar los bienes, porque ella debe crear la riqueza y la opulencia" (p. 28), mientras que la ciencia doméstica tiene por horizonte de sentido la producción y reproducción de la vida comunitaria y familiar, principalmente porque, es a la naturaleza, según palabras de Estagira, a quien le corresponde suministrar los alimentos para garantizar la reproducción de la vida, aun cuando la naturaleza, concebida de manera escindida de nuestra mismidad, es objeto de dominación para esta tradición civilizatoria. La ciencia doméstica se encargará de la administración de los recursos comunitarios y familiares para la vida.

Lo anterior refleja la tensión histórica desde la que se formaliza la actividad científica según la tradición helena, en la que culmina por imponerse la ciencia de adquirir, principalmente porque:

"es preciso a todo trance conservar o aumentar hasta el infinito la suma de dinero que se posee. Para llegar a conseguirlo, es preciso preocuparse únicamente del cuidado de vivir, sin cuidarse de vivir como se debe. No teniendo límites el deseo de la vida, se ve uno directamente arrastrado a desear, para satisfacerle, medios que no tiene. ... Teniendo el placer necesidad absoluta de una excesiva abundancia, se buscan todos los medios que pueden procurarla. Cuando no se pueden conseguir éstos con adquisiciones naturales, se acude a otras, y aplica uno sus facultades a usos a que no estaban destinadas por su naturaleza" (Aristóteles, 2007, p. 29).

7 De esto hemos dado cuenta, junto a Miguel Baraona, en un par de trabajos denominados: "El Estado como fundamento del proyecto imperialista", y "Hacia una epistemología radical de la descolonización", los dos de acceso gratuito en internet. 
A partir de lo anterior, se impulsa un solo tipo de ética con el proceso de formalización y expansión que sufre la ciencia a partir del siglo VI a.C., en la tradición helena. En este proceso de formalización quedan subsumidos los momentos educativos anteriores; pero, a partir de entonces, cuentan con un solo horizonte de sentido: "la riqueza ilimitada" (dominada por la racionalidad de la ciencia de adquirir), (Aristóteles, 2007). De esta forma quisiera atreverme a nombrar este séptimo momento educativo como momento de formalización de una racionalidad para el dominio, de lo cual nos ocuparemos en siguientes trabajos ${ }^{8}$.

El sentido de darle el nombre anterior a este séptimo momento educativo, tiene que ver con que, si bien la ciencia le ha permitido a nuestra especie dotarse de condiciones racionales ventajosas frente a todas las otras formas de vida producidas por nuestra madre común, irónicamente hemos producido las condiciones intelectuales y materiales para acabar con todas las formas de vida en el único cuerpo en la vía láctea, que conocemos, en capacidad de producirla (Baraona y Herra, 2016).

\section{A manera de balance}

La educación, como dinámica, es un proceso compuesto por dos momentos fundamentales: el aprendizaje y la enseñanza. Estos forman parte de un todo educativo desarrollado a lo largo de los cerca de 130.000 años que nuestra especie ha formado parte de la vida en la tierra. Lo que he propuesto como momentos educativos en este trabajo no debe ser entendido linealmente, sino como impulsos sincrónicos a través de los cuales el aprendizaje y la enseñanza le han permitido, a nuestra humanidad, enfrentarse a un entorno hostil e incomprensible.

Nuestra madre común, que nos ha dotado a todas las especies de habilidades distintas, nos ha permitido sofisticar las habilidades racionales a través de las que, desde hace unos 50.000-35.000 años, la nuestra logró imponerse como la única entre los otros tipos de homínido. La educación para ello fue esencial. A través de ella hemos podido hacer la vida comunitaria posible, pero a través de ella, se ha impulsado el desarrollo de las condiciones tecnológicas para la negación de la vida.

En el primer momento educativo propuesto, aprendizaje instintivo para la producción de la vida comunitaria, situado hacia el 130.000 a.C., nuestra especie recopiló distintos tipos de saberes pertinentes para poder hacer la vida posible. Fue en este momento cuando nuestra especie aprendió a discernir lo que le permitía o no la producción y reproducción de su mismidad. Dado que el saber adquirido, que en primera instancia es instintivo, urge de ser compartido con los miembros de la comunidad de la que forma parte, se da origen al segundo momento educativo al que he propuesto como enseñanza para la vida comunitaria. En este, la vida individual,

8 Alrededor de esta preocupación he escrito un artículo denominado “Determinaciones categoriales y noción conceptual de la educación. Una lectura crítica en torno al Sistema interregional Indoeuropeo" que se puede encontrar gratuitamente en Internet. 
singular, no es posible, dada la dependencia que como especie tenemos unas de otras, lo que impulsa al pueblo como primer sujeto productivo, dado que éste está sujeto a otro necesitado igual que él, que a través de la producción, satisface sus necesidades. La enseñanza para la vida comunitaria no es un acto meramente instintivo sino ya racionalizado, y le permitió a nuestra especie domesticar cereales como el trigo, en Egipto; el arroz, en China; la quinua, en Perú; o el maíz, en México.

Al tercer momento educativo identificado lo he propuesto como desarrollo de las condiciones técnicas para la negación de la vida. Este es un momento en el cual, como necesidad para garantizar la preservación de nuestra propia especie, ella se vuelca contra sí misma. Este momento, que comienza por ser un acto para la defensa se convertirá, más adelante, en el principal mecanismo de dominio y expansión de los distintos proyectos imperiales/coloniales que se extienden hasta la actualidad. Lo anterior es el fundamento por el cual la ciencia y la tecnología desarrollan sus principales avances en el campo militar y armamentístico: la negación de la vida.

Al cuarto momento educativo propuesto, lo he identificado como el origen de la tensión urbano/ rural, que es el momento histórico en el cual y por el cual, el desarrollo de la institucionalidad urbana se impone sobre la rural, privilegiando, a partir de entonces, el tipo de relaciones, interrelaciones, sentidos y significados de lo urbano sobre lo rural.

Se ha logrado identificar un premomento a todo momento educativo que he propuesto como acceso al agua como presupuesto de la vida, ya que no habría sido posible impulsar ningún horizonte ético, racional, político, económico, religioso o cultural sin acceso a la vida misma. De esta forma, el desplazamiento hacia aquellos espacios con acceso a fuentes de agua fue y sigue siendo un elemento esencial para la producción y reproducción de nuestra vida como especie.

Se ha identificado un quinto momento educativo constitutivo de la educación, que he propuesto como momento de espacialidad de lo divino y sacralidad del cielo, el cual se constituye en el momento en el que la respuesta divina, la cual cuenta con una espacialidad terrenal (el cielo), se impone sobre las otras posibles respuestas existentes ante las grandes preguntas, núcleos problemáticos, que ha enfrentado y enfrenta nuestra humanidad. Lo anterior tiende a institucionalizar y reproducir en adelante, las condiciones formales y luego reales de lo religioso, en la educación.

El sexto momento educativo, propuesto como saber teórico, dista del formalismo que caracterizará el proceder heleno posterior al siglo VI a.C. Sin embargo, la sofisticación en este tipo de pensamiento ético impulsa conceptos y categorías con qué representar las nociones de la nada o el infinito: el cero. Lo anterior permite comprender la muerte como el principio e inicio de la vida y a la vida como el principio e inicio de la muerte. La noción del cero, que refleja lo 
anterior, se le debe al sistema interregional egipcio-mesopotámico, a los indios, babilónicos y al sistema interregional mayo-azteca, quienes impulsaron desarrollos propios surgidos de forma desconectada.

Al séptimo momento educativo lo he propuesto como formalización de una racionalidad para el dominio. Este, está caracterizado por el desarrollo de respuestas a las preguntas surgidas en el marco de los núcleos problemáticos, cuyos niveles de sofisticación y formalización le han permitido a nuestra especie ya no solo disponer de un tipo de conocimiento para hacer la vida posible, sino incluso para dominarla.

El tipo de racionalización que se impulsa en este séptimo momento educativo produce un giro invertido en el campo de la ciencia, la cual desplaza una tradición de vocación y voluntad de servicio (ciencia doméstica), por otra de vocación y voluntad de dominio para con el ser humano y todas las otras formas de vida (ciencia de adquirir). Son estos los horizontes de sentido que tensan la posibilidad de la vida en la tierra y que atraviesan el tipo de razón impuesta en la ciencia y la filosofía de tradición occidental.

Siendo que el actual tiempo histórico que nos ha tocado vivir, enfrenta a la humanidad y a todas las formas de vida al peligro de no poder garantizar su producción y reproducción futura, tal como la conocemos en la actualidad, la educación se constituye en una de las principales herramientas técnicas para enfrentar dicho problema. Si bien el saber impuesto y los mecanismos que lo han permitido son producto de nuestra propia creación, será producto de nuestra creación que podamos, o no, enfrentar la complejidad a la que nos confronta nuestro tiempo histórico. Lograr identificar las determinaciones contenidas en la educación, para confrontarlas e ir más allá de las tensiones que cada una de ellas ha provocado en la posibilidad de producir y reproducir la vida a futuro, es clave en un tiempo en el que es la vida misma la que está en riesgo. La educación será clave para ello.

\section{Referencias bibliográficas}

Aristóteles. (2007). La política. México: Editorial Época.

Asimov, I. (2011). El cercano oriente. España: Alianza Editorial.

Baraona, M. y Herra, E. (2016). Danzando en la bruma junto al abismo. Costa Rica: Editorial Arlekín.

Bautista, J. (2010). Crítica a la razón boliviana. Elementos para una crítica de la subjetividad del boliviano con conciencia colonial, moderna y latinoamericana (3era ed.). Bolivia: Rincón ediciones. 
Dussel, E. (2009). Ética de la liberación en la edad de la globalización y de la exclusión. (6ta ed.). España: Editorial Trotta.

Dussel, E. (2011). Filosofía de la liberación. México: Fondo de Cultura Económica.

Dussel, E. (2014a). Hacia un Marx desconocido. Un comentario de los manuscritos del 61-63. México: Siglo XXI Editores.

Dussel, E. (2014b). 16 tesis de economía política. Interpretación filosófica. México: Ediciones Akal.

Dussel, E. (2015). Filosofías del sur. Descolonización y transmodernidad. México: Siglo XXI Editores.

Echeverría, R. (2015). Ontología del lenguaje. Argentina: Ediciones Gráfica S.A.

García, R. (2000). El conocimiento en construcción. De las formulaciones de Jean Piaget a la teoría de los sistemas complejos. España: Gedisa.

Herra, E. y Baraona, M. (2015a). El Estado como fundamento del proyecto Imperialista (Ponencia). Coloquio Internacional Antiimperialismo Latinoamericano: historia, memoria, tradiciones, legados y prácticas contemporáneas. Centro de Investigaciones sobre América Latina y el Caribe y Vicerrectoría de Extensión Universidad Nacional, Costa Rica. 13-15 de abril de 2015.

Herra, E. y Baraona, M. (2015b). Hacia una epistemología radical de la descolonización (Ponencia). XXX Congreso Latinoamericano de Sociología. "Pueblos en Movimiento: Un diálogo en las Ciencias Sociales". Mesa 16: Pensamiento Latinoamericano: Hacia la Descolonización de las Ciencias Sociales. 29 de noviembre al 4 de diciembre de 2015. Costa Rica, 2015.

Marcuse, H. (2014). El hombre unidimensional. (3era imp.). España: Editorial Ariel.

Leakey, R. y Lewin, R. (1999). Nuestros orígenes. En busca de lo que nos hace humanos. España: Editorial Crítica.

Prieto, C. (2010).Cinco milaños de palabras. Comentarios sobreel origen, evolución, muerteyresurrección de algunas lenguas. [3era ed.]. México: Fondo de Cultura Económica.

Quijano, A. (2000). Colonialidad del poder, eurocentrismo y América Latina. Recuperado de: http:// bibliotecavirtual.clacso.org.ar/ar/ libros/lander/quijano.rtf.

Waltari, M. (2005). S.P.Q.REl senador de Roma. España: EDHASA. 
Waltari, M. (2008). Sinuhe el egipcio. España: De bolsillo.

Zemelman, H. (2012). Pensar y poder. Razonar y gramática del pensar histórico. México: Siglo XXI Editores. 